Check for updates

Cite this: RSC Adv., 2019, 9, 20593

\title{
The potential of Thymus vulgaris aqueous extract to protect against delayed gastric emptying and colonic constipation in rats
}

\author{
Kaïs Rtibi, (D) *a Slimen Selmi, ${ }^{a}$ Dalanda Wannes, ${ }^{a}$ Mourad Jridi, ${ }^{\text {b }}$ Lamjed Marzouki ${ }^{a}$ \\ and Hichem Sebai ${ }^{a}$
}

Thyme is a rich source of bioactive phytochemicals and it is frequently used in folk-medicine to treat gastroenteritis irritations. The current study was performed to examine the potential of Thymus vulgaris aqueous extract (TV-AE) to protect against delayed gastric emptying (DGE) and colonic constipation in rats. Stomach ulcer was caused by a single oral dose administration of indomethacin (INDO) (30 mg kg of body weight). Constipation was induced following intravenous intoxication of rats with vinblastine (VINB) (2 mg kg-1 of body weight) for one week. The effect of TV-AE at two graduated doses (100 and $200 \mathrm{mg} \mathrm{kg}^{-1}$ ) on DGE, gastrointestinal transit (GIT) and constipated rats and biochemical parameters was estimated using phenol red, charcoal meal test and colorimetric methods, respectively. The phytochemical-profile of TV-AE was explored using high-performance liquid chromatography coupled with photodiode array detection and electrospray ionization-mass spectrometry (HPLC-PDA/ESI-MS). INDO and VINB caused a significant reduction in $(P<0.05)$ DGE and GIT and colonic motility dysfunction. TV-AE consumption remarkably $(P<0.05)$ attenuated the DGE (from $58.56 \%$ to $69.871 \%$ ) and difficulty in evacuating stools (from 48.5 to 55.5 fecal pellets per rat) and balanced the GIT (65\% to $71 \%)$. These Gl-ameliorative effects were accompanied by reversed INDO/VINB-related oxidative changes, lipid-metabolism alteration and intracellular pathway moderation. HPLC-PDA/ESI-MS-analysis identified several chemical constituents including rosmarinic acid, quinic acid, luteolin-7-o-glucoside, protocatechuic acid and trans-cinnamic acid. Thus, TV-AE bioactive components may be used as medicinal substances to regulate/attenuate gastrointestinal-physiological activities and disturbances, which support its pharmacological use.

Received 17th March 2019 Accepted 16th June 2019

DOI: $10.1039 / c 9 r a 02042 j$

rsc.li/rsc-advances remedy in the prevention/treatment of a variety of disorders such as gastroenteric and broncho-pulmonary disruptions. ${ }^{5}$ As reported by several researchers, thyme contains numerous phenolic compounds, especially thymol and carvacrol, which are found in its essential oil. Additionally, in wild-thyme, many other abundant phenolic compounds have been found such as caffeic and rosmarinic acid derivatives. ${ }^{6}$

Thymus vulgaris extract has different pharmacological activities, which were confirmed via in vivo and in vitro experiments, including immunomodulatory activity, anti-inflammatory effect, antibacterial ability, anthelmintic action, anti-oxidant activity, anti-thrombin capacity and potent antihypertensive ability. The therapeutic potential of Thymus vulgaris is based on its content of aliphatic phenols, flavonoids, thymol, carvacrol, and eugenol, in addition to luteolin and saponins. ${ }^{7-9}$

Functional gastrointestinal disorders (FGIDs) are defined by the perturbation of gastrointestinal tract sections such as gastroenteritis, ulcerative colitis, functional constipation and delayed gastric emptying (DGE). FGIDs, also known as disturbances of the gut-brain interaction, contain a number of separate idiopathic disruptions, which alter different regions of
${ }^{a}$ Laboratory of Functional Physiology and Valorization of Bio-resources-Higher Institute of Biotechnology of Beja, University of Jendouba, B. P. 382, 9000 Beja, Tunisia. E-mail: rtibikais@yahoo.fr; Fax: +216 72590 566; Tel: +216 97479135

${ }^{b}$ Laboratory of Enzymatic Engineering and Microbiology, National School of Engineers of Sfax, University of Sfax, B. P. 1173, 3038 Sfax, Tunisia 
the GI-tract and involve visceral motility disorders related to an oxidative stress installation. ${ }^{\mathbf{1 0 , 1 1}}$ Excessive ROS generation may contribute to cell injuries by lipid-protein-DNA oxidation in various tissues. ${ }^{12}$ In the GI tract, the cellular redox potential may even determine the fate of the differentiating cells. Wnt/ $\beta$-catenin and notch signaling pathways are the major determinants of cell commitment for specialization. There may be a direct association between NADPH oxidase 1 (NOX-1)-dependent ROS fabrication, differential provocation of Wnt/ $\beta$-catenin or notch signaling pathways, and intestinal proliferation. Modifications in the redox capacities of GSH/GSSG and cysteine/cystine (Cys/ CySS) have been integrated with intestinal phenotypic transitions. The reducing abilities may favor cell proliferation, but oxidizing efficiencies can lead to cell growth reduction or inhibition. ${ }^{13,14}$

There are no published reports in the literature about the effect of the extract of $T$. vulgaris on gastric emptying and functional constipation. Based on these considerations, this study was designed to characterize the various TV-AE phenolic components and to investigate the potentiality of TV-AE to protect the GI tract against gastric delayed emptying and colonic constipation in rats.

\section{Materials and methods}

\subsection{Chemicals}

Clonidine, red phenol, $\mathrm{NaCl}, \mathrm{NaOH}$, charcoal meal, gum arabic, and haematoxylin/eosin were purchased from Sigma Chemical Co. (Sigma-Aldrich GmbH, Steinheim, Germany). Indomethacin and vinblastine were purchased from a local central pharmacy. All other reagents used were of analytical grade.

\subsection{TV-AE preparation}

T. vulgaris leaves were collected from the region of Jendouba (North-West of Tunisia) during the season of spring (2017). Voucher specimens were identified and authenticated by a taxonomist in the Higher Institute of Biotechnology of Beja Tunisia and deposited at the herbarium in the Faculty of Sciences, University of El Manar, Tunisia. The leaves were dried at $40{ }^{\circ} \mathrm{C}$ in air, ground, and extracted with bi-distilled water. The obtained leaf extracts were dehydrated at the same temperature under vacuum and finally freeze dried.

\subsection{TV-AE bioactive compound identification by liquid chromatography-high-resolution electrospray ionization mass spectrometry (LC-HRESIMS) assay}

$100 \mathrm{mg}$ of TV-AE was dissolved in $100 \mathrm{~mL}$ of $10 \%$ methanol, filtered and then $1 \mathrm{~mL}$ was added to LC-MS vials. A reversephase column (Pursuit XRs ULTRA 2.8, C18, $100 \times 2 \mathrm{~mm}$, Agilent Technologies, UK) was used to perform HPLC examinations. $20 \mathrm{~mL}$ of the sample was injected at a column temperature set at $30{ }^{\circ} \mathrm{C}$. The mobile phase consisted of $0.1 \%$ formic acid in water (A) and $0.1 \%$ formic acid in methanol (B). A gradient program was used for separation at a flow rate of 1 $\mathrm{mL} \mathrm{min}^{-1}$. The mobile phase consisted of an initial composition of $100 \%$ solvent A, with a gradient of $100 \%$ solvent B over
$20 \mathrm{~min}$, held at $100 \%$ solvent B for $5 \mathrm{~min}$ and $100 \%$ solvent A for

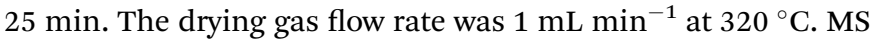
was operated in the positive ion mode in the mass range of 100$2000 \mathrm{~m} / \mathrm{z}$. High-resolution mass spectral data was obtained on a Thermo Instruments ESI-MS system (LTQ XL/LTQ Orbitrap Discovery, UK) connected to a Thermo Instruments HPLC system (Accela PDA Detector, Accela PDA Autosampler and Accela Pump). ${ }^{15}$

\subsection{Animals}

Male Wistar rats (180 and $220 \mathrm{~g}$ ) were used at 13 weeks of age. The animals were obtained from the Society of Pharmaceutical Industries of Tunisia (SIPHAT, Ben-Arours, Tunisia), and isolated into different groups and acclimatized for two weeks with a standard pellet diet (standard pellet diet Badr-Utique-TN) and water ad libitum $\left(22 \pm 2{ }^{\circ} \mathrm{C} ; 12 \mathrm{~h}\right.$ dark per light cycle $)$. All animal procedures were performed in accordance with the Guidelines for Care and Use of Laboratory Animals of Tunis University and approved by the Animal Ethics Committee of National Institute of Health. ${ }^{16}$

\subsection{Experimental design}

2.5.1. Acute DGE and CON inductions in rats. Acute UG was caused in the animals according to the procedure described by Oluwabunmi and Abiola. ${ }^{17}$ Briefly, the rats were administered with a single oral dose of indomethacin $\left(30 \mathrm{mg} \mathrm{kg}^{-1}\right.$ body weight). The animals were deprived of food for $24 \mathrm{~h}$ but had free access to water prior to ulcer induction. Various degrees of ulceration manifested $4 \mathrm{~h}$ after indomethacin administration. Acute UG diagnosis was evaluated by different clinical signs, such as gastric juice volume, ulcer score and gastric $\mathrm{pH}$. Colonic alterations were caused in vivo according to the method elucidated by Rtibi et al. ${ }^{18}$ Briefly, animals were intoxicated with intravenous injection of vinblastine $\left(2 \mathrm{mg} \mathrm{kg} \mathrm{kg}^{-1}\right.$ of body weight in a saline solution) for 7 days. Diagnosis of VINB injuries was confirmed by several signs, such as fecal pellet, wet fecal weight, dry fecal weight and water content.

2.5.2. TV-AE and drug actions on GIT in healthy and treated rats. This manipulation was carried out according to our previous studies using the charcoal meal test. ${ }^{19}$ Specifically, after $2 \mathrm{~h}$ of animal treatment with TV-AE at two doses (100 and $\left.200 \mathrm{mg} \mathrm{kg}^{-1}\right)$ or the standard molecule $\left(1 \mathrm{mg} \mathrm{kg}^{-1}\right)$, the colitis rats were provided the standard charcoal meal $10 \%$ charcoal in $5 \%$ gum arabic) by oral administration. After $30 \mathrm{~min}$, the animals were anesthetized and their small bowel was excised. The distance travelled by the charcoal meal suspension was measured and expressed as a percentage of the total length. The peristaltic index was calculated using the following formula:

Peristaltic index $=($ distance travelled by charcoal meal/length of small-intestine) $\times 100$

$\%$ of inhibition $=$ mean distance travelled by the control - mean distance travelled by the test group/mean distance travelled by the control. 
2.5.3. INDO and TV-AE effects on gastric emptying process. To assess the INDO/TV-AE actions on the gastric-emptying process, the red phenol method was used. In this context, the animals were divided into different groups of seven and administered $1 \mathrm{~h}$ before with the test meal (50 $\mathrm{mg}$ phenol red in $100 \mathrm{~mL}$ aqueous methyl cellulose) as follows: group 1 served as the control group (CONT) and received $1 \mathrm{~mL}$ of physiological solution ( $\mathrm{NaCl}, 0.9 \%$, p.o.). Groups 2 and 3 were treated only with the extract. Group 4 served as the INDO group without extract and drug. Groups 5 and 6 of INDO rats were pre-treated with two doses of TV-AE (100 and $200 \mathrm{mg} \mathrm{kg}^{-1}$, b.w. p.o.).

After $1 \mathrm{~h}$, the animals were anesthetized and euthanized. Their stomach and its contents were combined with $100 \mathrm{~mL}$ of $0.1 \mathrm{~N} \mathrm{NaOH}$. The supernatants were mixed with $4 \mathrm{~mL}$ of $0.5 \mathrm{~N}$ $\mathrm{NaOH}$ and the absorbance of the samples was read at $560 \mathrm{~nm}$. Phenol red collected immediately from stomach organs after test meal administration was used as the standard ( $0 \%$ of GE) ${ }^{20}$

GE (\%) was calculated according to the following formula:

Gastric emptying rate $(\%)=(1-$ absorbance of treated/ absorbance of standard) $\times 100$.

2.5.4. VINB and TV-AE effects on colonic motor activity. The animals were randomly divided into four groups. Healthy animals or the control group (CONT) received a physiological solution at a dose of $5 \mathrm{~mL} \mathrm{~kg}^{-1}(n=7)$. The VINB group was treated intravenously only with VINB ( $2 \mathrm{mg} \mathrm{kg}^{-1}$ b.w.) dissolved in a saline solution once per day for one week $(n=7)$. Finally, the two other groups were treated by VINB in combination with TV-AE at two doses of $100 \mathrm{mg} \mathrm{kg}^{-1}$ and $200 \mathrm{mg} \mathrm{kg}^{-1}(n=7)$. On day 5 , the faecal pellet weights (wet and dry weights) of the rats were measured for $24 \mathrm{~h}$ and the water levels were determined by the difference between the weights before and after drying. ${ }^{18}$

2.5.5. Oxidative and antioxidative marker assessment in rats. Gastric and colonic mucosal tissues were scraped and then placed in a phosphate buffered saline (PBS) solution, homogenized and centrifuged for $15 \mathrm{~min}$ at $9000 \times \mathrm{g}$. The obtained aliquots were stored at $-80{ }^{\circ} \mathrm{C}$.

Lipid oxidation caused by ROS and free radicals in the UG/ UC rats led to MDA production, which was estimated with double heating technique adapted by Draper et $a .^{21}$ The expression of the results was reported as the mean of MDA nmol $\mathrm{mg}^{-1}$ of proteins. Thiol group $(-\mathrm{SH})$ content was determined using Ellman's procedure ${ }^{22}$ and the data was expressed as nmol of $-\mathrm{SH}$ per $\mathrm{mg}$ of proteins. Carbonyl residue generation after protein oxidation was examined using the method by Levine et $a .^{23}$ The results were expressed as $\mu \mathrm{mol}$ carbonyl residue per mg protein.

Superoxide dismutase action was determined using the nicotinamide adenine dinucleotide (reduced) phenazine methosulphate nitroblue tetrazolium reaction system method. ${ }^{24}$ The results were calculated and expressed in units of SOD per mg proteins. Catalase (CAT) activity was estimated using the procedure by $\mathrm{Aebi}^{25}$ and the results were expressed as $\mathrm{nmol} \mathrm{min}^{-1} \mathrm{mg}^{-1}$ protein. GPx activity was analysed using the
Flohé and Günzler design ${ }^{26}$ and the data was expressed as nmol GSH $\min ^{-1} \mathrm{mg}^{-1}$ protein.

2.5.6. Lipid indicators and moderating intracellular pathways assessment in rats. After blood centrifugation at $3000 \times g$ for $10 \mathrm{~min}$, the lipid marker (triglycerides, total cholesterol, and high-density cholesterol) contents were measured in the asobtained serum using commercially available kits purchased from Biomaghreb, Tunisia.

Gastric and colonic mucosal $\mathrm{H}_{2} \mathrm{O}_{2}$ levels were determined according to the method by Dingeon et $a .^{27}$ and the data was expressed as $\mu \mathrm{mol}$ of $\mathrm{H}_{2} \mathrm{O}_{2}$ per $\mathrm{mg}$ protein. Intracellular mediators (calcium and non-haem iron) levels were measured using commercial kits purchased from Biomaghreb, Tunisia. ${ }^{28,29}$ The results were expressed as nmol of these parameters per mg protein.

\subsection{Statistical analysis}

A one-way analysis of variance test was used to determine the significance between the different groups of all animals. Statistical analyses were calculated using StatView statistical software. The data is representative of six to eight distinct observations. Differences were stated as mean \pm SEM and designated significant when the values of $p$ were $<0.05$.

\section{Results and discussion}

\subsection{Phytochemical composition}

It has been reported that thyme has been considered for long time as a good source of phenolic compounds. ${ }^{30}$ In this respect, HPLC-PDA/ESI-MS analysis revealed the presence of 27 phenolic-compounds in TV-AE, including rosmarinic acid, quinic acid, luteolin-7-o-glucoside, protocatechuic acid, trans cinnamic acid, caffeic acid, naringenin, kaempferol, quercetin, apigenin, rutin, 3,4-di-O-caffeoylquinic acid, syringic acid, $p$ coumaric acid, naringin, acacetin, hyperoside (quercetin-3- $o$ galactoside), quercetrin (quercetin-3-o-rhamonosid), gallic acid, trans ferulic acid, apigenin-7-o-glucoside, 4-O-caffeoylquinic acid, chlorogenic acid, silymarin, catechin $(+)$, luteolin and $o$ coumaric acid (Fig. 1 and Table 1). Moreover, according to previous research, the phenolic profile of thyme obtained with HPLC-PDA/ESI-MS analysis showed diverse phenolic compounds such as rosmarinic acid, quinic acid, luteolin-7-Oglucoside, protocatechuic acid, trans cinnamic acid, caffeic acid, naringenin, kaempferol, quercetin, apigenin, rutin, 3,4-di$O$-caffeoylquinic acid, syringic acid, $p$-coumaric acid, naringin, acacetin, hyperoside (quercetin-3-o-galactoside), quercetrin (quercetin-3-o-rhamonosid), gallic acid, trans ferulic acid, apigenin-7-o-glucoside, 4-O-caffeoylquinic acid, chlorogenic acid, silymarin, catechin $(+)$, luteolin and $o$-coumaric acid. ${ }^{31}$ Importantly, many researchers (in vitro, in silico and in vivo) have proven the structure-activity relationship of bioactive compounds such as phenolic acids and flavonoids with their biological properties. In this respect, the bioactivity of these compounds depends mostly on the number of hydroxyl groups linked to the aromatic ring and their relative orientation in the molecular structure. ${ }^{32}$ 

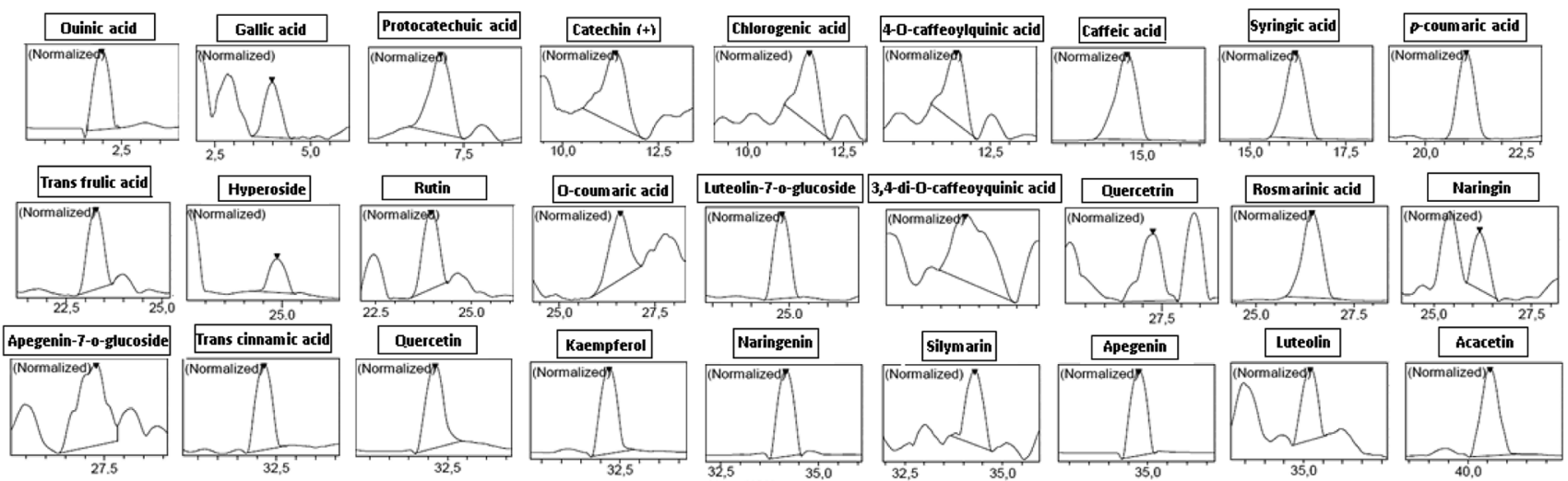

Fig. 1 Chromatographic profiles and characterization of phenolic compounds in TV-AE.

\subsection{TV-AE consumption accelerates GIT in healthy and constipated rats}

Chemotherapy-induced constipation (CIC) is a persistent problem in the treatment of different types of cancer, and is among the primary contributors to dose decreases, delays and inefficient treatment. ${ }^{33}$ In the VINB rats, the overall gastrointestinal motor activity analysed by the progression of the test meal through the small-bowel was significantly $(P<0.05)$ reduced $(65.12 \pm 1.66 \%)$ compared to those in the healthy animals $(70.65 \pm 3.63 \%)$. However, TV-AE administration at both doses resulted in a significant $(P<0.05)$ improvement in gastrointestinal transit in both the healthy (77.92 \pm 3.45 and $83.74 \pm 2.88 \%$, respectively) and VINB rats (68.90 \pm 2.18 and $71.33 \pm 3.46 \%$, respectively) (Table 2). Furthermore, the rats receiving VINB showed several signs, including severe difficulty in evacuating stools, which was observed in the CON model compared with the healthy group. This effect was confirmed by the faecal parameter disorders noticed in the VINB group at day 5 , including faecal pellets and water content diminution ( $48.64 \pm 3.21$ fecal pellets and $27.66 \pm 2.63 \%$ water content) in comparison with the control-group $(56.23 \pm 3.00$ fecal pellets and

Table 1 High-resolution liquid chromatography/electrospray ionization (LC-HRESIMS) TV-AE component identification

\begin{tabular}{|c|c|c|c|c|c|}
\hline Name $^{a}$ & Molecular formula & PubChem CID & {$[\mathrm{M}]^{-} \mathrm{H}^{b} \mathrm{~m} / \mathrm{z}$} & Retention time & Concentration (ppm) \\
\hline Quinic acid & $\mathrm{C}_{7} \mathrm{H}_{12} \mathrm{O}_{6}$ & 6508 & 191.00 & 1.978 & 364.647 \\
\hline Gallic acid & $\mathrm{C}_{7} \mathrm{H}_{6} \mathrm{O}_{5}$ & 370 & 169.00 & 3.989 & 6.688 \\
\hline Protocatechuic acid & $\mathrm{C}_{7} \mathrm{H}_{6} \mathrm{O}_{4}$ & 72 & 153.00 & 6.890 & 46.790 \\
\hline Catechin $(+)$ & $\mathrm{C}_{15} \mathrm{H}_{14} \mathrm{O}_{6}$ & 73160 & 289.00 & 11.382 & 1.311 \\
\hline Chlorogenic acid & $\mathrm{C}_{16} \mathrm{H}_{18} \mathrm{O}_{9}$ & 1794427 & 353.00 & 11.615 & 2.493 \\
\hline 4-O-Caffeoylquinic acid & $\mathrm{C}_{16} \mathrm{H}_{18} \mathrm{O}_{9}$ & 5281780 & 353.00 & 11.612 & 2.558 \\
\hline Caffeic acid & $\mathrm{C}_{9} \mathrm{H}_{8} \mathrm{O}_{4}$ & 689043 & 179.00 & 14.603 & 37.468 \\
\hline Syringic acid & $\mathrm{C}_{9} \mathrm{H}_{10} \mathrm{O}_{5}$ & 10742 & 197.00 & 16.190 & 24.471 \\
\hline$p$-Coumaric acid & $\mathrm{C}_{9} \mathrm{H}_{8} \mathrm{O}_{3}$ & 637542 & 163.00 & 21.061 & 17.003 \\
\hline trans Ferulic acid & $\mathrm{C}_{10} \mathrm{H}_{10} \mathrm{O}_{4}$ & 445858 & 193.00 & 23.276 & 3.501 \\
\hline Hyperoside (quercetin-3-o-galactoside) & $\mathrm{C}_{21} \mathrm{H}_{20} \mathrm{O}_{12}$ & 5281643 & 463.00 & 24.864 & 10.149 \\
\hline Rutin & $\mathrm{C}_{27} \mathrm{H}_{30} \mathrm{O}_{16}$ & 5280805 & 609.00 & 23.941 & 28.653 \\
\hline$o$-Coumaric acid & $\mathrm{C}_{9} \mathrm{H}_{8} \mathrm{O}_{3}$ & 637540 & 163.00 & 26.598 & 1.258 \\
\hline Luteolin-7-o-glucoside & $\mathrm{C}_{21} \mathrm{H}_{20} \mathrm{O}_{11}$ & 5280637 & 447.00 & 24.800 & 46.983 \\
\hline 3,4-Di-O-caffeoylquinic acid & $\mathrm{C}_{25} \mathrm{H}_{24} \mathrm{O}_{12}$ & 5281780 & 515.00 & 25.146 & 24.494 \\
\hline Quercetrin (quercetin-3-o-rhamnoside) & $\mathrm{C}_{21} \mathrm{H}_{20} \mathrm{O}_{11}$ & 15939939 & 447.00 & 27.267 & 7.219 \\
\hline Rosmarinic acid & $\mathrm{C}_{18} \mathrm{H}_{16} \mathrm{O}_{8}$ & 5315615 & 359.00 & 26.434 & 5066.278 \\
\hline Naringin & $\mathrm{C}_{27} \mathrm{H}_{32} \mathrm{O}_{14}$ & 442428 & 579.00 & 26.168 & 11.984 \\
\hline Apigenin-7-o-glucoside & $\mathrm{C}_{21} \mathrm{H}_{20} \mathrm{O}_{10}$ & 45933926 & 431.00 & 27.291 & 3.393 \\
\hline trans Cinnamic acid & $\mathrm{C}_{9} \mathrm{H}_{8} \mathrm{O}_{2}$ & 444539 & 147.00 & 32.184 & 41.109 \\
\hline Quercetin & $\mathrm{C}_{15} \mathrm{H}_{10} \mathrm{O}_{7}$ & 5280343 & 301.00 & 32.175 & 35.730 \\
\hline Kampherol & $\mathrm{C}_{15} \mathrm{H}_{10} \mathrm{O}_{6}$ & 5280863 & 285.00 & 32.218 & 35.972 \\
\hline Naringenin & $\mathrm{C}_{15} \mathrm{H}_{12} \mathrm{O}_{5}$ & 439246 & 271.00 & 34.164 & 37.425 \\
\hline Silymarin & $\mathrm{C}_{25} \mathrm{H}_{22} \mathrm{O}_{10}$ & 31553 & 481.00 & 34.290 & 1.547 \\
\hline Apigenin & $\mathrm{C}_{15} \mathrm{H}_{10} \mathrm{O}_{5}$ & 5280443 & 269.00 & 34.768 & 35.701 \\
\hline Luteolin & $\mathrm{C}_{15} \mathrm{H}_{10} \mathrm{O}_{6}$ & 5280445 & 285.00 & 35.175 & 1.270 \\
\hline Acacetin & $\mathrm{C}_{16} \mathrm{H}_{12} \mathrm{O}_{5}$ & 5280442 & 283.00 & 40.566 & 11.362 \\
\hline
\end{tabular}

${ }^{a}$ The compounds are suggested according to the dictionary of natural products and the characteristic fragmentation pattern. ${ }^{b}$ The formulas were deduced from the quasi molecular ion peak $[\mathrm{M}+\mathrm{H}]^{+}$. 
Table 2 VINB/TV-AE actions on gastrointestinal motility in healthy and intoxicated rats ${ }^{a}$

\begin{tabular}{lllll}
\hline Group & Dose & Gastro-intestinal motility (\%) & Reduction activity (\%) & Reinforcement (\%) \\
\hline Control $(\mathrm{NaCl})$ & $\left(5 \mathrm{~mL} \mathrm{~kg}^{-1}\right)$ & $70.65 \pm 3.63$ & - & - \\
Clonidine & $\left(1 \mathrm{mg} \mathrm{kg}^{-1}\right)$ & $28.23 \pm 1.77^{*}$ & 60.04 & - \\
VINB & $\left(2 \mathrm{mg} \mathrm{kg}^{-1}\right)$ & $65.12 \pm 1.66^{*}$ & 07.82 & - \\
TV-AE alone & $\left(100 \mathrm{mg} \mathrm{kg}^{-1}\right)$ & $77.92 \pm 3.45^{* \#}$ & - & 10.29 \\
& $\left(200 \mathrm{mg} \mathrm{kg}^{-1}\right)$ & $83.74 \pm 2.88^{* \#}$ & - & 18.52 \\
VINB/TV-AE & $\left(100 \mathrm{mg} \mathrm{kg}^{-1}\right)$ & $68.90 \pm 2.18^{\#}$ & - & 5.80 \\
& $\left(200 \mathrm{mg} \mathrm{kg}^{-1}\right)$ & $71.33 \pm 3.46^{\#}$ & 09.53
\end{tabular}

${ }^{a}$ Rats were intoxicated with VINB $\left(2 \mathrm{mg} \mathrm{kg}{ }^{-1}\right)$ for one week. Then, the animals were treated with two increasing doses of TV-AE or reference molecule (clonidine, $\left.1 \mathrm{mg} \mathrm{kg}^{-1}\right) .2 \mathrm{~h}$ later, the rats were given the standard charcoal meal $(10 \%$ charcoal in $5 \%$ gum arabic) or vehicle (NaCl, $0.9 \%)$. Data are expressed as mean \pm standard error $(n=7) ;{ }^{*} P<0.05$ versus control group, ${ }^{\#} P<0.05$ versus VINB-group.

$39.08 \pm 3.10 \%$ water content) (Table 3 ). These alterations were combined with histopathological-injuries, ${ }^{34,35}$ which provoked loss of fluidity/permeability. These eruptions were accompanied with equilibrium disruption of the absorption/secretion of water, electrolytes and nutrients, which led to diverse variations in the gastrointestinal physiological functions, such as GIT. TV-AE administration removed these disruptions, and thus allowed the construction of the mucosa, as shown by the histological study and the facilitation of intestinal and colonic contents advancement. ${ }^{36,37}$

Actually, the exact mechanisms of the action of CIC remain unclear, but are believed to result from the association of intersecting processes, including GI dysmotility, secretory dysfunction, inflammation and alterations in GI innervation. ${ }^{33}$

TV-AE may contain many bioactive compounds that behave as purgatives/stimulate, which activates the gut musculature by acting on the nerve endings of the colon and causing movements that promote defecation. They also act on the walls of the intestine and increase mineral/liquid production, while lessening the absorption of sodium/chlorine. ${ }^{38}$

In addition, interstitial cells of Cajal (ICCs) appear to play crucial roles in the physiological GI motility modulation and act as the pacemaker of gastrointestinal movement. In this respect, we think that TV-AE can depolarize the membrane potentials of ICCs. This excitation may lead to smooth muscle cells via a gap junction. These last cells may respond to this depolarization with the activation of voltagedependent $\mathrm{Ca}^{2+}$ channels. ${ }^{39}$ Therefore, this action of pacemaker potential depolarization may produce intensification of the intestinal motility rate. For this point, many recent research showed that diverse traditional herbal medicines such as Schisandra chinensis, ${ }^{40}$ Ge-Gen-Tang, ${ }^{41}$ Liriope platyphylla ${ }^{42}$ and Citrus unshiu ${ }^{\mathbf{4 3}}$ demonstrated elicit excitatory/ inhibitory effects on the ICC pacemaker activity, which supports the notion that ICCs are critical in the control of smooth muscle motility in the GI tract.

Direct assessments of calcium currents in single smooth muscle cells by the whole cell voltage clamp methods in the rat and mouse colons showed a 50-70\% decrease in $\mathrm{Ca}^{2+}$ ion flux after an inflammatory response. Akbarali et al. ${ }^{44}$ established that in addition to the down-regulation of $\mathrm{Ca}^{2+}$ currents, the response to the ATP-sensitive $\mathrm{K}^{+}$channel agonist lemakalim improved in the inflamed smooth muscle cells. Likewise, colonic irritation results in contracted contractions of colonic muscle strips in both human/animal models of colitis to depolarizing $\mathrm{K}^{+}$solutions. In particular, recent studies indicated that transient receptor potential vanilloid-4 (TRPV4) activation in the GI tract induces intracellular calcium accumulation, chemokine release enhancement, and colitis reinforcement. In contrast, antiinflammatory compounds significantly diminished TRPV4expression in the upper-intestine. ${ }^{\mathbf{4 5 , 4 6}}$

\subsection{TV-AE consumption facilitates the emptying process in healthy and INDO group}

NSAIDs stimulate gastric ulcers via the suppression of prostaglandins, which are cytoprotective constituents to the gastric

Table 3 Identification of parameters following acute drug disorders and TV-AE effects ${ }^{a}$

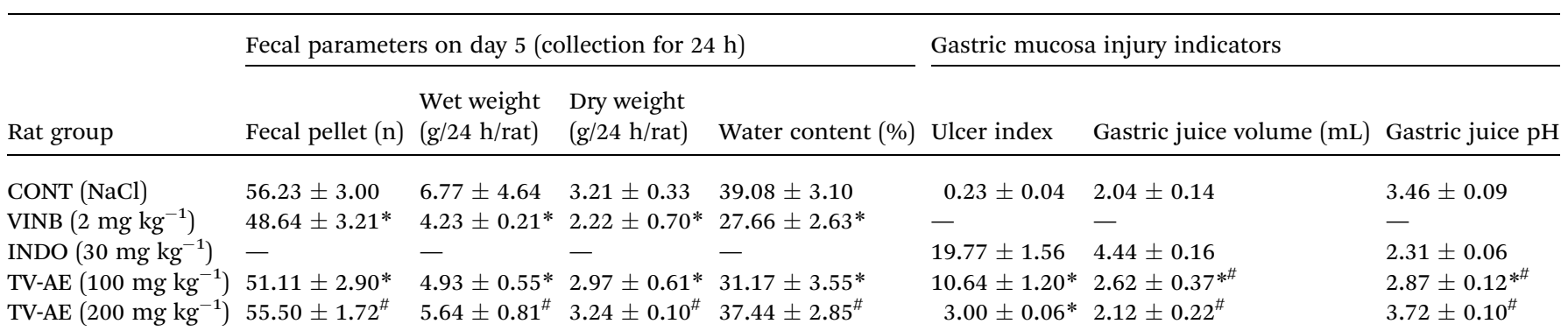

${ }^{a}$ VINB/INDO alterations reflected by indicated parameters and assessed in healthy rats and rats treated with VINB $\left(2 \mathrm{mg} \mathrm{kg}^{-1}\right) \mathrm{or}^{\mathrm{INDO}}(30 \mathrm{mg}$ $\left.\mathrm{kg}^{-1}\right)$. Data are expressed as mean \pm standard error $(n=7) ;{ }^{*} P<0.05$ versus control group, ${ }^{\#} P<0.05$ versus VINB/INDO groups. 
mucosal tissues, specifically due to the COX pathway disturbance of arachidonic acid metabolism, resulting in the massive generation of leukotrienes and other factors such as that of the 5-lipoxygenase enzyme metabolic pathway. ${ }^{47}$

INDO administration at a dose of $30 \mathrm{mg} \mathrm{kg}^{-1}$ produced acute ulcerative gastritis in the animals. This damage was manifested by an increase in the ulcer index and gastric juice volume and a significant reduction in $\mathrm{pH}$. These disruptive actions were accompanied with a delayed gastric emptying effect. ${ }^{17}$ TV-AE at both concentrations induced a significant $(P<0.05)$ acceleration of normal gastric emptying $(81.52 \pm 2.67 \%$ and $89.05 \pm 3.44 \%$, respectively) when the results are compared to that found in the healthy animals $(70.25 \pm 1.45 \%)$. In the ulcerative gastritis situation, the acquired data showed that the gastric emptying time analysed by the red phenol method strongly $(P<0.05)$ decreased in the gastric ulcer situation $(58.56 \pm 0.78 \%)$. In contrast, comparatively with the ulcerative gastritis group, TV-AE pre-treatment attenuated UG and remarkably accelerated $(P<0.05)$ the gastric emptying time (62.40 $\pm 0.99 \%$ and $69.87 \pm 1.66 \%$, respectively) (Fig. 2).

Natural small molecules produced from medicinal plants have been used for a long time to treat and prevent diverse ailments. Recently, the use of natural medicine in the treatment of various pathologies like peptic ulcer is an absolute requirement. Therefore, an alternative advance in recent days is the research of phytomedicaments serving as a tool in the prevention of peptic ulcers. ${ }^{48}$ Several phytocomponents such as flavonoids, tannins, terpenoids, and saponin have been reported in distinct anti-ulcer findings as possible gastro-protective agents. Rosmarinic acid is known to be facilely absorbed from the gastrointestinal tract into the blood. It activates prostaglandin E2 generation, diminishes leukotriene B4 production in human leucocytes, and inhibits the complement system. It is also proven that caffeic acid and derivatives such as rosmarinic acid have therapeutic potential in the treatment/prevention of spasmogenic disruptions, peptic ulcers, and inflammatory disorders. ${ }^{49}$

\subsection{TV-AE consumption relieves and ameliorates oxidative and antioxidative balance}

In both INDO/VINB groups, the obtained results showed an oxidative stress installation, which is related with an enzymatic antioxidant disruption following a massive ROS/free radical generation. These injuries were confirmed by the increase in MDA production and carbonyl protein formation in the UG/UC conditions, and associated with the depletion of enzyme activities, such as SOD, CAT and GPx. However, TV-AE consumption at both different doses (100 and $200 \mathrm{mg}$ $\mathrm{kg}^{-1}$ ) relieved oxidative damage and ameliorated/stimulated the antioxidant profile (Fig. 3 and 4 ).

A recent study clearly exhibited the participation of oxidative stress/inflammation in gastrointestinal problems such as ulcers and constipation. ${ }^{50}$ This contribution was checked by the augmentation of intracellular ROS production, which induces damage to lipids, proteins and DNA and inflammatory indicators. Iron catalyzes hydroxyl radical- mediated oxidative injury through its implication in the Fenton pathway, which leads to the reduction of this element in oxidative stress condition. Many authors showed that the phenolic compounds of thyme extract have greater antioxidant activity compared to $\alpha$-tocophenol and butylated-hydroxylanisole. Rosmarinic acid (RA), the most important component of the thyme extract, has strong antioxidative activity since it acts as a free radical scavenger. ${ }^{51}$ Further research suggested other possible mechanisms for the protection of RA against lipid peroxidation, including the scavenging effect of numerous radical species, interaction with peroxyl-radicals and partitioning into the LDL particle and terminating chain reactions of oxidative degradation of lipids by scavenging lipid radicals. ${ }^{52}$ An alternative hypothesis is that antioxidant supplements modulate endogenous mechanisms that either decrease ROS production or increase the enzymes activities that decompose ROS. ${ }^{53}$

\subsection{TV-AE consumption improves lipid metabolisms/ intracellular mediators disruptions in intoxicated rats by drugs}

To investigate the cell level damage and modifications in lipid metabolism, we studied the effect of drugs on lipidemia indicators as well as intracellular mediators. Accordingly, we observed a significant $(P<0.05)$ increase in $\mathrm{H}_{2} \mathrm{O}_{2}$ production in both eruptions, which was accompanied by a depletion of calcium and free iron. TG, TC and HDL cholesterol were significantly $(P<0.05)$ altered in the GU condition. However, the bioactive compounds and mineral constituents in TV-AE resulted in protection against all these disruptions (Table 4).

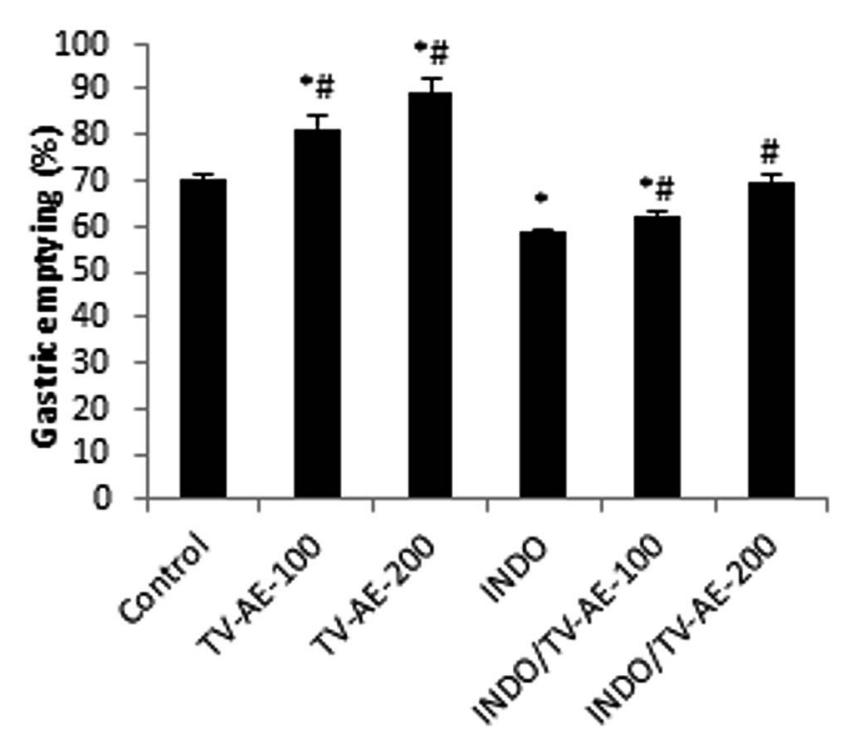

Fig. 2 Effect of TV-AE on INDO-induced delayed gastric emptying. Animals were treated $1 \mathrm{~h}$ prior to the test meal $(50 \mathrm{mg}$ phenol red in $100 \mathrm{~mL}$ aqueous methyl cellulose) with two doses of TV-AE (100 and $200 \mathrm{mg} \mathrm{kg}^{-1}$ ). Results are expressed as mean $\pm \mathrm{SEM} ; n=7$ in each group. Data was analyzed by Statview ANOVA. * $P<0.05$ compared to control group, ${ }^{\#} P<0.05$ compared to INDO group. 
(a)
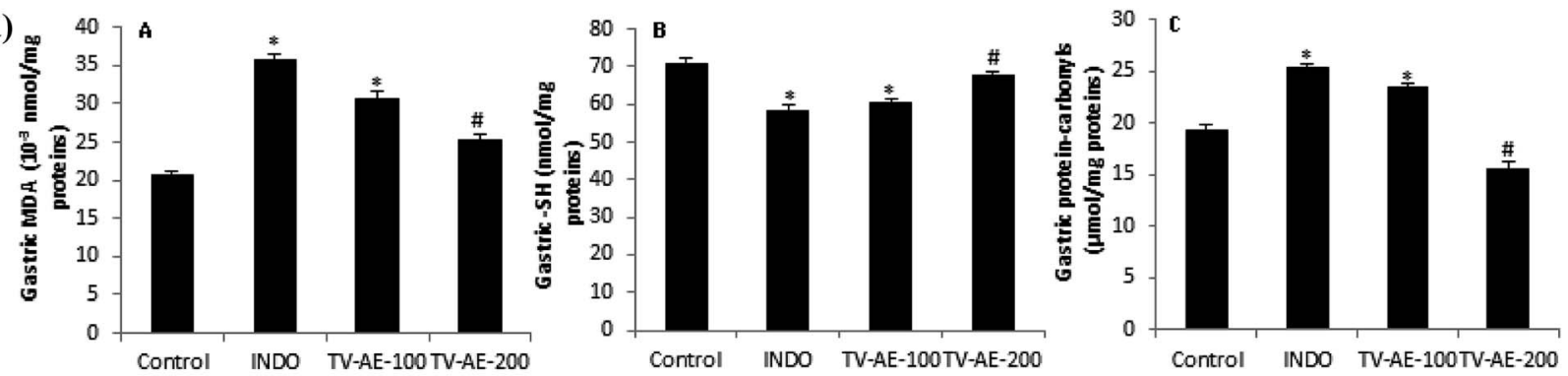

(b)
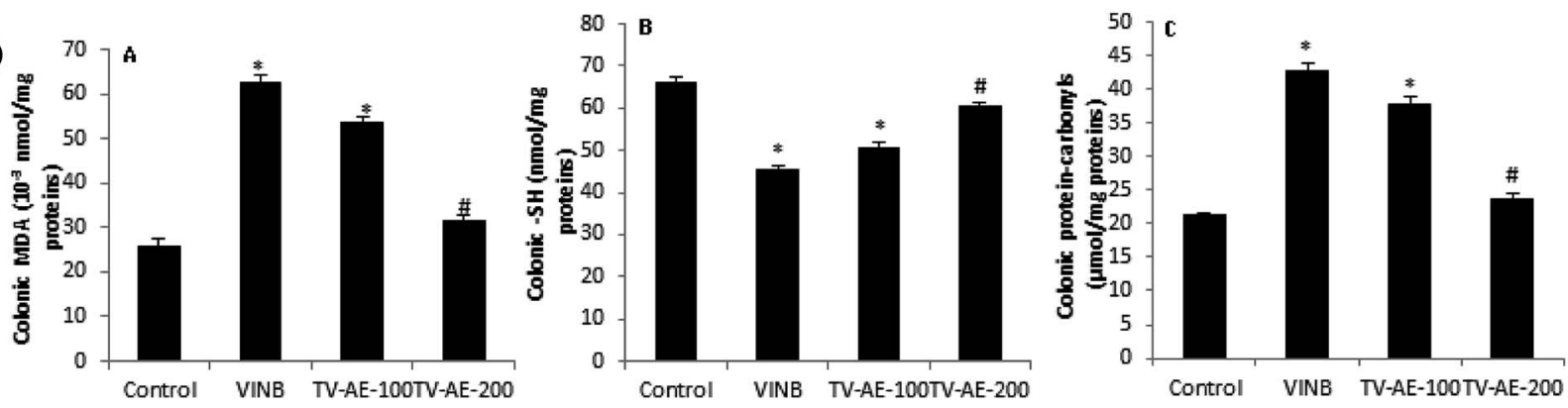

Fig. 3 (a and b) Acute effect of TV-AE (100 and $200 \mathrm{mg} \mathrm{kg}^{-1}$, respectively) on INDO/VINB-induced changes in gastric and colonic mucosal MDA, $\mathrm{SH}$ group and protein carbonyls levels. ${ }^{*} P<0.05$ compared to control group, ${ }^{*} P<0.05$ compared to INDO and VINB-groups. Values are means \pm $\operatorname{SEM}(n=7)$

Previous studies demonstrated that RA exhibited substantial $\mathrm{H}_{2} \mathrm{O}_{2}$ scavenging action and inhibited $\mathrm{H}_{2} \mathrm{O}_{2}$-induced intracellular ROS generation. ${ }^{54}$ The data also showed that the lipid components such as triglyceride, total cholesterol, and HDL cholesterol contents were remarkably different among the major groups (Table 5). A recent study reported that many bioactive components such as gallic acid, catechin, and epicatechin have cholesterol-lowering activities by reducing pancreatic cholesterol esterase activity, binding of bile acids, and inhibiting solubility of cholesterol in micelles, which may result in delayed cholesterol absorption. These flavonoids may also reduce cholesterol absorption via interaction with cholesterol carriers and transporters across the brush border membrane in rats. ${ }^{55}$ Abdulkarimi et al. ${ }^{4}$ showed that thyme extract consumption decreased the plasma triglyceride, total cholesterol, LDL-c and VLDL-c, which in turn lowered the liver and abdominal lipids, and reduced the proportional liver and abdominal fat weights. These actions were exerted by the lower activity of the HMG-CoA reductase enzyme, diminished fat absorption from the gastrointestinal tract or the lipid catabolism for the gluconeogenesis process.
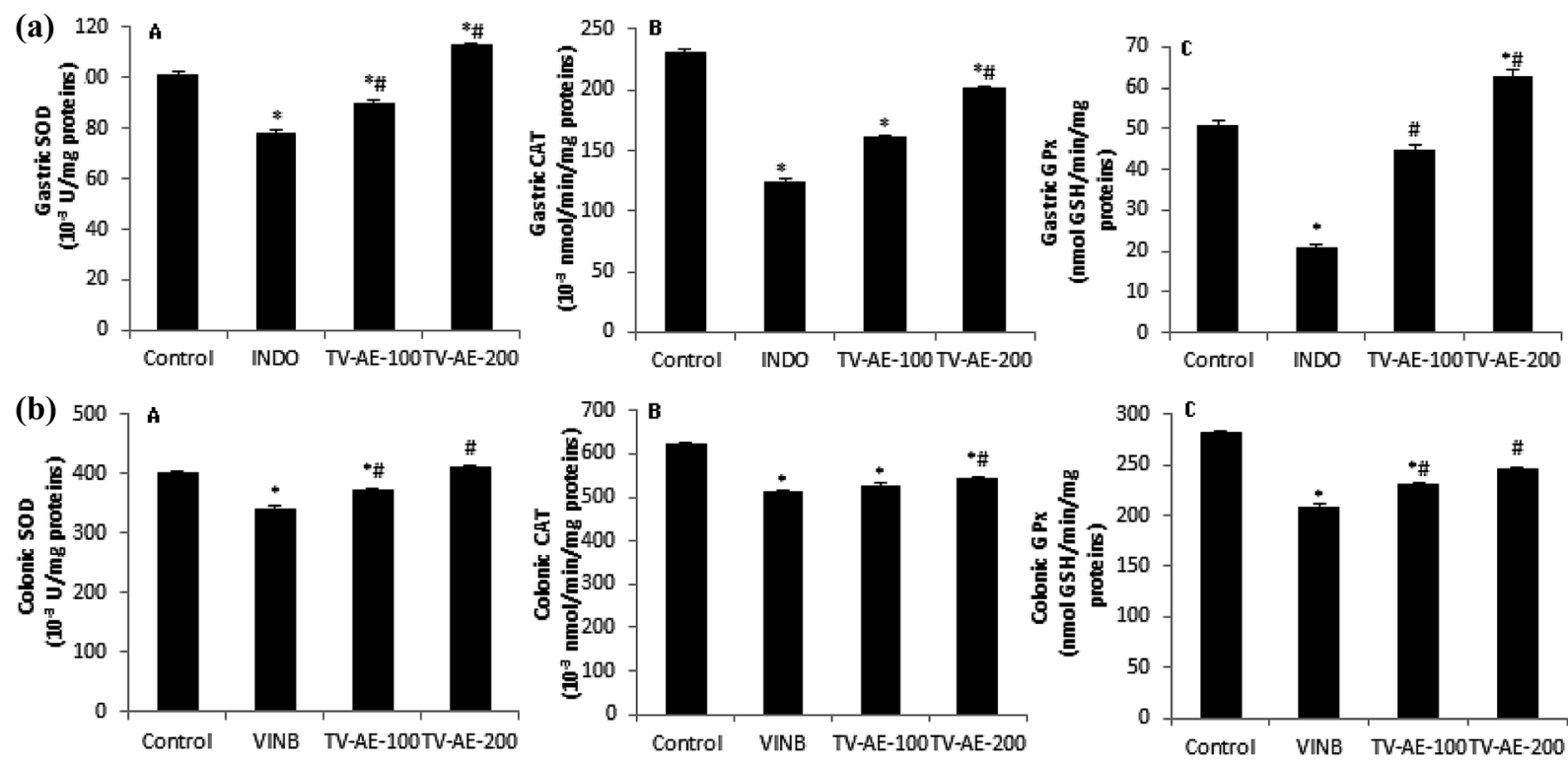

Fig. 4 (a and b) Acute effect of TV-AE (100 and $200 \mathrm{mg} \mathrm{kg}^{-1}$, respectively) on INDO/VINB-induced depletion in gastric and colonic mucosal enzymatic antioxidant activities. ${ }^{*} P<0.05$ compared to control-group, ${ }^{*} P<0.05$ compared to INDO and VINB-groups. Values are means \pm SEM $(n=7)$. 
Table 4 VINB/INDO/TV-AE actions on intracellular mediator disturbances in healthy and treated rats ${ }^{a}$

\begin{tabular}{|c|c|c|c|c|}
\hline Group & Dose & $\mathrm{H}_{2} \mathrm{O}_{2}\left(\mu \mathrm{mol} \mathrm{mg}{ }^{-1}\right.$ protein $)$ & $\begin{array}{l}\text { Free iron }(\mathrm{nmol} \\
\mathrm{mg}^{-1} \text { protein) }\end{array}$ & $\begin{array}{l}\text { Calcium }\left(10^{-3}\right. \\
\left.\text { nmol } \mathrm{mg}^{-1} \text { protein }\right)\end{array}$ \\
\hline CONT (NaCl) & $\left(5 \mathrm{~mL} \mathrm{~kg}^{-1}\right)$ & $09.05 \pm 0.33$ & $11.34 \pm 0.06$ & $33.67 \pm 3.57$ \\
\hline VINB/TV-AE & $\begin{array}{l}\left(100 \mathrm{mg} \mathrm{kg}^{-1}\right) \\
\left(200 \mathrm{mg} \mathrm{kg}^{-1}\right)\end{array}$ & $\begin{array}{l}24.70 \pm 2.11^{* \#} \\
11.98 \pm 1.22^{\#}\end{array}$ & $\begin{aligned} 9.24 & \pm 0.21 \\
10.24 & \pm 0.06^{\#}\end{aligned}$ & $22.99 \pm 0.84^{*}$ \\
\hline INDO & $\left(30 \mathrm{mg} \mathrm{kg}^{-1}\right)$ & $37.33 \pm 2.29^{*}$ & $04.28 \pm 0.07^{*}$ & $21.38 \pm 1.01^{*}$ \\
\hline
\end{tabular}

${ }^{a}$ VINB/INDO/TV-AE effects were reflected by intracellular mediators assessed in healthy rats and rats treated with VINB $\left(2 \mathrm{mg} \mathrm{kg}^{-1}\right)$ or INDO $(30 \mathrm{mg}$ $\left.\mathrm{kg}^{-1}\right)$. Results are expressed as mean $\pm \mathrm{SEM} ; n=7$ in each group. Data was analyzed by Statview ANOVA. Data are expressed as mean \pm standard error $(n=7) ;{ }^{*} P<0.05$ versus control group, ${ }^{\#} P<0.05$ versus VINB/INDO-groups.

Table 5 VINB/INDO/TV-AE actions on serum lipid metabolism disruptions in healthy and treated rats ${ }^{a}$

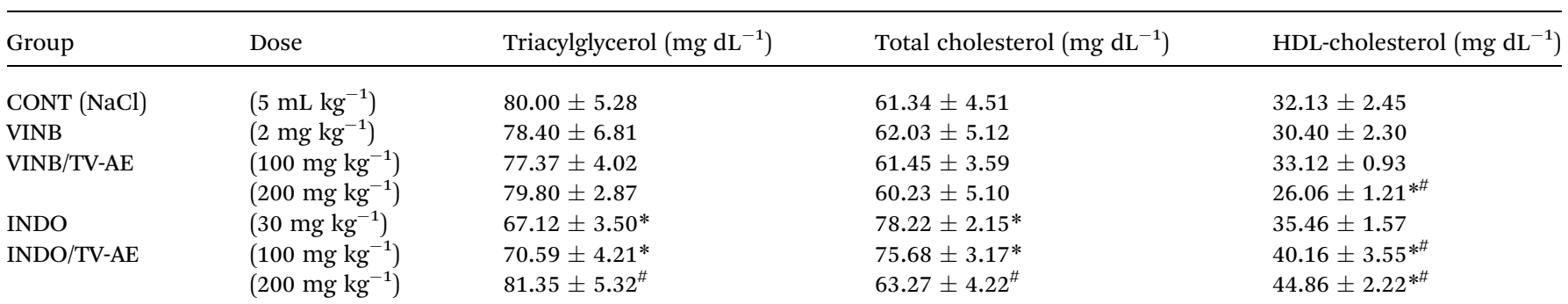

${ }^{a}$ VINB/INDO/TV-AE effects were reflected by serum lipid metabolism assessed in healthy rats and rats treated with VINB $\left(2 \mathrm{mg} \mathrm{kg}^{-1}\right)$ or INDO $(30 \mathrm{mg}$ $\left.\mathrm{kg}^{-1}\right)$. Results are expressed as mean $\pm \mathrm{SEM} ; n=7$ in each group. Data was analyzed by Statview ANOVA. Data are expressed as mean \pm standard error $(n=7) ;{ }^{*} P<0.05$ versus control group, ${ }^{\#} P<0.05$ versus VINB/INDO-groups.

\section{Conclusion}

The current study demonstrated that TV-AE represents a source of bioactive functional components and may contribute an improvement in gastrointestinal physiological actions and their associated disorders in rats via various mechanisms. Consequently, this investigation supports the therapeutic potential and strong possibility of TV-AE as a functional food in phytomedicine, which should be further explored in clinical studies.

\section{Financial disclosures}

None declared.

\section{Conflicts of interest}

Only the authors are responsible for the content of this paper.

\section{Abbreviations}

$\begin{array}{ll}\text { GET } & \text { Gastric emptying time } \\ \text { GIT } & \text { Gastrointestinal transit } \\ \text { GPx } & \text { Glutathione peroxidase } \\ \text { GU } & \text { Gastric ulcer } \\ \text { HDL } & \text { High density lipoproteins } \\ \text { HPLC-PDA/ } & \text { Liquid chromatography-photodiode-array-mass } \\ \text { ESI-MS } & \text { spectrometry } \\ \text { ICCs } & \text { Interstitial cells of Cajal } \\ \text { INDO } & \text { Indomethacin } \\ \text { MDA } & \text { Malondialdehyde } \\ \text { NOX-1 } & \text { NADPH-oxidase 1 } \\ \text { NSAIDs } & \text { Nonsteroidal anti-inflammatory drugs } \\ \text { ROS } & \text { Reactive oxygen species } \\ \text { SOD } & \text { Superoxide dismutase } \\ \text { TC } & \text { Total cholesterol } \\ \text { TG } & \text { Triglycerides } \\ \text { TRPV4 } & \text { Transient receptor potential vanilloid-4 } \\ \text { TV-AE } & \text { Thymus } \text { vulgaris } \text { aqueous extract } \\ \text { UC } & \text { Ulcerative colitis } \\ \text { UG } & \text { Ulcerative gastritis } \\ \text { VINB } & \text { Vinblastine }\end{array}$

\section{Acknowledgements}

Financial support of Tunisian Ministry of Higher Education and Scientific Research is gratefully acknowledged. 


\section{References}

1 T. Lang, Functional foods, Br. Med. J., 2007, 334, 1015-1016.

2 A. Santini, S. M. Cammarata, G. Capone, A. Ianaro, G. C. Tenore, L. Pani and E. Novellino, Nutraceuticals: opening the debate for a regulatory framework, Br. J. Clin. Pharmacol., 2018, 84, 659-672.

3 C. Xu, R. Zhang and Z. Wen, Bioactive compounds and biological functions of sea cucumbers as potential functional foods, J. Funct. Foods, 2018, 49, 73-84.

4 R. Abdulkarimi, M. Daneshyar and A. Aghazadeh, Thyme (Thymus vulgaris) extract consumption darkens liver, lowers blood cholesterol, proportional liver and abdominal fat weights in broiler chickens, Ital. J. Anim. Sci., 2011, 10, e20.

5 E. M. A. Dauqan and A. Abdullah, Medicinal and Functional Values of Thyme (Thymus vulgaris L.) Herb, J. Appl. Biol. Biotechnol., 2017, 5, 017-022.

6 A. Komaki, F. Hoseini, S. Shahidi and N. Baharlouei, Study of the effect of extract of Thymus vulgaris on anxiety in male rats, J. Tradit. Complement. Med., 2016, 6, 257-261.

7 H. G. D. Dorman and S. G. Deans, Antimicrobial Plants: Antibacterial Activity of Plant, Appl. Microbiol., 2000, 88, 308-316.

8 M. Khani, P. Motamedi, M. R. Dehkhoda, S. DabaghNikukheslat and P. Karimi, Effect of thyme extract supplementation on lipid peroxidation, antioxidant capacity, PGC-1 $\alpha$ content and endurance exercise performance in rats, J. Int. Soc. Sports Nutr., 2017, 14, 11.

9 Z. Amirghofran, H. Ahmadi and M. H. Karimi, Immunomodulatory activity of the water extract of Thymus vulgaris, Thymus daenensis, and Zataria multiflora on dendritic cells and $\mathrm{T}$ cells responses, J. Immunoassay Immunochem., 2012, 33, 388-402.

10 D. A. Drossman, Functional Gastrointestinal Disorders: History, Pathophysiology, Clinical Features and Rome IV, Gastroenterology, 2016, 150, 1262-1279.

11 D. Liu, L. Gao, J. Zhang, X. Huo, H. Ni and L. Cao, Antiinflammatory and Anti-oxidant Effects of Licorice Flavonoids on Ulcerative Colitis in Mouse Model, Chin. Herb. Med., 2017, 9, 358-368.

12 Y. S. Bae, H. Oh, S. G. Rhee and Y. D. Yoo, Regulation of Reactive Oxygen Species Generation in Cell Signaling, Mol. Cell, 2011, 32, 491-509.

13 W. H. Watson, J. D. Ritzenthaler and J. Roman, Lung extracellular matrix and redox regulation, Redox Biol., 2016, 8, 305-315.

14 I. Khan, S. E. Samson and A. K. Grover, Antioxidant Supplements and Gastrointestinal Diseases: A Critical Appraisal, Med. Prin. Pract., 2017, 26, 201-217.

15 N. Hajji, M.-A. Jabri, H. Tounsi, D. Wanes, I. Ben El Hadj Ali, A. Boulil, L. Marzouki and H. Sebai, Phytochemical analysis by HPLC-PDA/ESI-MS of Globularia alypum aqueous extract and mechanism of its protective effect on experimental colitis induced by acetic acid in rat, J. Funct. Foods, 2018, 47, 220-228.
16 National Research Council, Guide for the Care and the Use of Laboratory Animals, National Institute of Health, Bethesda, 1985, vol. 20, p. 85.

17 I. J. Oluwabunmi and T. Abiola, Gastroprotective effect of methanolic extract of Gomphrena celosioides on indomethacin induced gastric ulcer in Wistar albino rats, Int. J. Appl. Basic Med. Res., 2015, 5, 41-45.

18 K. Rtibi, D. Grami, S. Selmi, M. Amri, H. Sebai and L. Marzouki, Vinblastine, an anticancer drug, causes constipation and oxidative stress as well as others disruptions in intestinal tract in rat, Toxicol. Rep., 2017, 4, 221-225.

19 K. Rtibi, S. Selmi, M. A. Jabri, G. Mamadou, N. Limas-Nzouzi, H. Sebai, J. El-Benna, L. Marzouki, B. Eto and M. Amri, Effects of aqueous extracts from Ceratonia siliqua L. pods on small intestinal motility in rats and jejunal permeability in mice, $R S C A d v ., 2016,6$, 44345-44353.

20 K. Rtibi, S. Selmi, K. Saidani, D. Grami, M. Amri, H. Sebai and L. Marzouki, Reverse effect of Opuntia ficus-indica L. juice and seeds aqueous extract on gastric emptying and small-bowel motility in rat, J. Food Sci., 2018, 83, 205-211.

$21 \mathrm{H}$. H. Draper and M. Hadley, Malondialdehyde determination as index of lipid peroxidation, Methods Enzymol., 1990, 186, 421-431.

22 G. E. Ellman, Tissue sulfhydryl groups, Arch. Biochem. Biophys., 1959, 82, 70-77.

23 L. R. Levine, D. Garland, C. N. Oliver, A. Amici, I. Climent, A. G. Lenz, B. W. Ahn, S. Shaltiel and E. R. Stadtman, Determination of carbonyl content in oxidatively modified proteins, Methods Enzymol., 1990, 186, 464-478.

24 P. Kakkar, B. Das and P. N. Viswanathan, Modified spectrophotometric assay of SOD, Indian J. Biochem. Biophys., 1984, 2, 130-132.

25 H. Aebi, Catalase, in Methods in Enzymatic Analysis, ed. H. U. Bergmeyer, Academic Press Inc., New York, 1974, pp. 673686.

26 L. Flohé and W. A. Günzler, Assays of glutathione peroxidase, Methods Enzymol., 1984, 105, 114-121.

27 B. Dingeon, J. P. Ferry and A. Roullet, Auto analysis of blood sugar by Trinder's method, Ann. Biol. Clin., 1975, 33, 3-13.

28 A. Leardi, M. Caraglia, C. Selleri, S. Pepe, C. Pizzi, R. Notaro, A. Fabbrocini, S. De Lorenzo, M. Musico, A. Abbruzzese, A. R. Bianco and P. Tagliaferri, Desferrioxamine increases iron depletion and apoptosis induced by ara-C of human myeloid leukaemic cells, Br. J. Haematol., 1998, 102, 746-752.

29 J. Stern and W. H. Lewis, The colorimetric estimation of calcium in serum with ocresolphthalein-complexone, Clin. Chim. Acta, 1957, 2, 576-580.

30 A. A. El-Nekeety, S. R. Mohamed, A. S. Hathout, N. S. Hassan, S. E. Aly and M. A. Abdel-Wahhab, Antioxidant properties of Thymus vulgaris oil against aflatoxin-induce oxidative stress in male rats, Toxicon, 2011, 57, 984-991.

31 M. H. H. Roby, M. A. Sarhan, K. A. H. Selim and K. I. Khalel, Evaluation of antioxidant activity, total phenols and phenolic compounds in thyme (Thymus vulgaris L.), sage (Salvia officinalis L.), and marjoram (Origanum majorana L.) extracts, Ind. Crops Prod., 2013, 43, 827-831. 
32 D. L. Ambriz-Pérez, N. Leyva-López, E. P. Gutierrez-Grijalva and J. B. Heredia, Phenolic compounds: natural alternative in inflammation treatment a review, Cogent Food Agric., 2016, 2, 1131412.

33 M. M. Rachel, S. Vanesa, A. Raquel, C. B. Joel and N. Kulmira, Chemotherapy-Induced Constipation and Diarrhea: Pathophysiology, Current and Emerging Treatments, Front. Pharmacol., 2016, 7, 414.

34 S. H. Han, K. Park, E. Y. Kim, S. H. Ahn, H. S. Lee and H. J. Suh, Cactus (Opuntia humifusa) water extract ameliorates loperamide-induced constipation in rats, $B M C$ Complementary Altern. Med., 2017, 17, 49.

35 A. Jaja-Chimedza, B. L. Graf, C. Simmler, Y. Kim, P. Kuhn, G. F. Pauli and I. Raskin, Biochemical characterization and anti-inflammatory properties of an isothiocyanate-enriched moringa (Moringa oleifera) seed extract, PLoS One, 2017, 12, e0182658.

36 S. Roth, M. R. Spalinger, C. Gottier, L. Biedermann, J. Zeitz, S. Lang, A. Weber, G. Rogler and M. Scharl, Bilberry-Derived Anthocyanins Modulate Cytokine Expression in the Intestine of Patients with Ulcerative Colitis, PLoS One, 2016, 11, e0154817.

37 S. Sabiu and O. T. Ashafa, Toxicological implications and laxative potential of ethanol root extract of Morella serrata in loperamide-induced constipated Wistar rats, Pharm. Biol., 2016, 54, 2901-2908.

38 P. Holzer, Opioid receptors in the gastrointestinal tract, Regul. Pept., 2009, 155, 11-17.

39 G. D. S. Hirst and F. R. Edwards, Role of Interstitial Cells of Cajal in the Control of Gastric Motility, J. Pharmacol. Sci., 2004, 96, 1-10.

40 T. S. Ahn, D. G. Kim, N. R. Hong, H. S. Park, H. Kim, K. T. Ha, J. H. Jeon, I. So and B. J. Kim, Effects of Schisandra chinensis extract on gastrointestinal motility in mice, $J$. Ethnopharmacol., 2015, 169, 163-169.

41 S. Lee, H. Gim, J. H. Shim, K. H. Jung, J. R. Lee, S. C. Kim, Y. K. Kwon, K. T. Ha, I. So and B. J. Kim, The traditional herbal medicine, Ge-Gen-Tang, inhibits pacemaker potentials by nitric oxide/cGMP dependent ATP-sensitive $\mathrm{K}(+)$ channels in cultured interstitial cells of Cajal from mouse small intestine, J. Ethnopharmacol., 2015, 170, 201209.

42 H. J. Kim, S. Y. Park, D. G. Kim, S. H. Park, H. Lee, D. Y. Hwang, M. H. Jung, K. T. Ha and B. J. Kim, Effects of the roots of Liriope platyphylla Wang Et tang on gastrointestinal motility function, J. Ethnopharmacol., 2016, 26(184), 144-153.

43 J. H. Shim, S. J. Lee, H. Gim, H. J. Kim, T. Han, J. G. Kim, E. Y. Lim, Y. T. Kim and B. J. Kim, Regulation of the pacemaker activities in cultured interstitial cells of Cajal by Citrus unshiu peel extracts, Mol. Med. Rep., 2016, 14, 3908-3916.
44 H. I. Akbarali, E. G. Hawkins, G. R. Ross and M. Kang, Ion channel remodeling in gastrointestinal inflammation, Neurogastroenterol. Motil., 2010, 22, 1045-1055.

$45 \mathrm{~J}$. Fichna, A. Mokrowiecka, A. I. Cygankiewicz, P. K. Zakrzewski, E. Małecka-Panas, A. Janecka, W. M. Krajewska and M. A. Storr, Transient receptor potential vanilloid 4 blockade protects against experimental colitis in mice: a new strategy for inflammatory bowel diseases treatment?, Neurogastroenterol. Motil., 2012, 24, e557-e560.

$46 \mathrm{~N}$. Vergnolle, TRPV4: new therapeutic target for inflammatory bowel diseases, Biochem. Pharmacol., 2014, 89, 157-161.

47 R. S. Pandian, C. V. Anuradha and P. Viswanathan, Gastroprotective effect of fenugreek seeds (Trigonella foenum-graecum) on experimental gastric ulcer in rats, $J$. Ethnopharmacol., 2002, 81, 393-397.

48 D. Sasmal, S. Das and S. P. Basu, Phytoconstituents and therapeutic potential of Nyctanthes arbortristis Linn, Pharmacol. Rev., 2007, 1, 344-349.

49 M. Petersen and M. S. Simmonds, Rosmarinic acid, Phytochemistry, 2003, 62, 121-125.

50 K. Rtibi, D. Grami, D. Wannes, S. Selmi, M. Amri, H. Sebai and L. Marzouki, Ficus carica aqueous extract alleviates delayed gastric emptying and recovers ulcerative colitisenhanced acute functional gastrointestinal disorders in rats, J. Ethnopharmacol., 2018, 224, 242-249.

51 S. Maqsood, S. Benjakul, A. Abushelaibi and A. Alam, Phenolic compounds and plant phenolic extracts as natural antioxidants in prevention of lipid oxidation in seafood: a detailed review, Compr. Rev. Food Sci. Food Saf., 2014, 13, 1125-1140.

52 H. Ahmadvand, A. Khosrobeigi, L. Nemati, M. Boshtam, N. Jafari, R. H. Hosseini, Y. Pournia, H. Ahmadvand, A. Khosrobeigi, L. Nemati, M. Boshtam, N. Jafari, R. H. Hosseini and Y. Pournia, Rosmarinic acid prevents the oxidation of low density lipoprotein (LDL) in vitro, $J$. Biol. Sci., 2012, 12, 301-307.

53 H. J. Forman, K. J. Davies and F. Ursini, How do nutritional antioxidants really work: nucleophilic tone and parahormesis versus free radical scavenging in vivo, Free Radical Biol. Med., 2014, 66, 24-35.

54 H. J. Hahn, K. B. Kim, I. S. An, K. J. Ahn and H. J. Han, Protective effects of rosmarinic acid against hydrogen peroxide-induced cellular senescence and the inflammatory response in normal human dermal fibroblasts, Mol. Med. Rep., 2017, 16, 9763-9769.

55 S. Ngamukote, K. Mäkynen, T. Thilawech and S. Adisakwattana, Cholesterol-lowering activity of the major polyphenols in grape seed, Molecules, 2011, 16, 5054-5061. 